\title{
The killing fields
}

\section{J. R. S. Fincham}

The Last Harvest: The Genetic Gamble that Threatens to Destroy American Agriculture. By Paul Raeburn. Simon and Schuster: 1995. Pp. 269. \$24.

SuCCESSFUL plant breeding depends on a pool of genetic variation to which selection can be applied. But by producing highly productive varieties that take over large sectors of the market, its natural tendency is to drive much of that variation out of existence. At the same time, the reservoir of wild species from which cultivated plants were derived and could in principle be regenerated is constantly being diminished by commercial development and population pressure. There has to be concern about the ability of plant breeders to meet future crises, whether brought about by new pests and diseases or by climatic change.

Paul Raeburn provides a highly readable survey of these issues for the layman. $\mathrm{He}$ is a journalist rather than a scientist, but he has consulted and quotes a broad range of scientific authorities, including representatives of seed companies as well as academic botanists and ecologists. He wants to raise the alarm, but nevertheless his book is not the apocalyptic tract that its catchpenny title and subtitle would lead one to expect. The careful reader can come away with a broad and balanced picture of the problem.

There are two ways in which genetic diversity for future breeding can be conserved: through seed banks and through conservation of wild plants in their natural habitats. The United States, on which this book is mainly focused, has large publicly funded seed banks, including the National Seed Storage Laboratory, said to hold about a quarter of a million samples of different species and cultivars, and the National Small Grains Collection, which houses 112,000 different accessions of all the commonly grown cereals, including rice.

Raeburn highlights the difficulties and hazards in the maintenance of such extensive collections. The policy at the National Seed Storage Laboratory is to grow and regenerate more seed from any sample whose viability drops below 65 per cent, but it emerged from Raeburn's enquiries that nearly two-thirds of the collection had never been tested for its ability to germinate, either because of lack of staff or because the numbers of seeds were too small to risk in a test. Ideally, all these small samples should be grown into plants for generation of more adequate quantities of seed but, given the general difficulty of getting funding for things whose usefulness has not yet been demonstrated, one cannot be surprised that this has not been done. The evaluation of the agronomic potential of each and every seed sample would obviously be a very much greater job, yet without such evaluation the collection is not readily usable. Directors of seed banks have to do the best they can with limited resources, and they may well be haunted by Raeburn's chapter heading: "Seed Banks and Seed Morgues".

Regarding the preservation of species in the wild, there are some success stories but not enough. Raeburn cites the Sierra some exaggeration, on its "almost magical ability to shuffle genes as easily as a deck of cards", but he assumes that desirable genes for incorporation into crops would have to come ready-made from nature rather than by in vitro reconstruction based on knowledge of how they work. This may well be to underrate the power of genetic engineering, but at least one can agree that it is never likely to make natural variation redundant.

How imminent is the crisis of genetic impoverishment foreseen in Raeburn's book? The examples that he cites from the recent history of US agriculture are as much of problems overcome as of disasters. The infestation in the late 1980s of the wheat and barley crop by Russian aphid was countered, though with much effort and over many years, by the development of resistant varieties incorporating genes from several Middle Eastern strains available in the National Small

\section{IMAGE UNAVAILABLE FOR COPYRIGHT REASONS}

Crops in crisis: Recent cases of genetic impoverishment in US agriculture are examples of problems overcome rather than disasters.

de Manantlan Biosphere Reserve, run by the University of Guadalajara in Mexico, which is home to upwards of 2,500 plant species, including a perennial maize. But the establishment of such reserves around the world will depend not only on the political stability of the countries concerned but also on successful diplomacy. Most of the world's plant species, including nearly all of those still to be discovered, are in poor countries increasingly inclined to demand a price for the exploitation, or even the exploration, of their native floras. Raeburn recounts how Thomas Jefferson enriched his country's agriculture by smuggling rice seeds out of Piedmont in Italy, thereby risking execution by the Piedmontese. Though no doubt praiseworthy at the time, this kind of botanical piracy can hardly be defended today.

Raeburn's position on genetic engineering is ambivalent. He remarks, with
Seeds Collection. Such examples might well suggest to the optimist that plant breeders have genetic resources sufficient to keep agriculture going, at least for the time being. But, in the longer term, radical changes in growing conditions brought about, for example, by soil deterioration and all the consequences of global warming if and when it occurs, could force changes both in methods of cultivation and in the kinds of plants grown. Raeburn, in his final chapter, advocates a return to smallerscale (and presumably more labourintensive) farming, with a greater diversity of crops.

The key to the maintenance of genetic diversity is, of course, money. How much can we afford?

J. R. S. Fincham is at the Division of Biological Sciences, University of Edinburgh, Edinburgh EH9 3JN, UK. 